\title{
Utilization of Ionic Liquids for Low Temperature Dyeing of Proteinic Fabrics
}

\author{
A. Kantouch, E.M. Khalil", S. Mowafi, O.G. Allam and \\ H. El-Sayed ${ }^{\#}$ \\ Textile Research Division, National Research Centre and \\ *Department of Chemistry, Science Collage, Helwan University, \\ Cairo, Egypt.
}

\begin{abstract}
A ACCEPTABLE method was developed for dyeing of wool and A silk fabrics at $60{ }^{\circ} \mathrm{C}$ using acid and reactive dyes. Two commercially available ionic liquids (ILs); namely 1-ethyl 3-methyl imidazolium acetate (EMIA), and 1-butyl 3-methyl imidazolium chloride (BMIC), in aqueous or non-aqueous medium, as diluents, were utilized to enhance the dyeability of wool and silk fabrics with the selected dyes. The effect of the amount (\%) of IL as well as treatment time and temperature on the dyeability of wool was assessed. Pre-swelling of both fabrics in either EMIA or BMIC, highly improved their dyeability with acid and reactive dyes at $60^{\circ} \mathrm{C}$, compared with the untreated fabrics. The washing and rubbing fastness of the untreated as well as pre-treated dyed wool fabrics were assessed.
\end{abstract}

Keywords: Wool, Silk, Ionic Liquids, Dyeing, Acid, Reactive and Dyes .

The term ionic liquid (IL) refers to organic or inorganic ionic salts whose melting points are relatively low, non-measureable vapour pressure, limited flammability, and high thermal stability ${ }^{(1)}$. The first group of ionic liquids was launched in 1876 as syrupy liquids based on $\mathrm{N}$-alkylpicolinium halides ${ }^{(2,3)}$. At the beginning of $20^{\text {th }}$ century, an important group of ionic liquids based on anilinium salts were introduced into the market ${ }^{(4-6)}$. The ionic liquid consist mainly of an organic cation, such as 1-alkyl-3-methylimidazolium, 1-alkyl pyridinium, or 1-methyl-1-alkyl pyrrolidinium and counter-ions such as halides, acetate, ethyl sulphate, tetraflouro borate, and hexaflouro phosphate..., etc. Lately, there have been marvelous advances in our knowledge about the ability of ionic liquids to dissolve textile substrates and wastes thereof ${ }^{(7-11)}$.

Conventional methods in wool dyeing involve prolonged periods at or near the boil within the $\mathrm{pH}$ range of 2-7 to obtain good leveling and penetration into the fibre. Under these conditions the fibre may be damaged as a result of hydrolysis of the protein components ${ }^{(12)}$.

\#e-mail: hosam@trdegypt.org 
The present work aims at developing an economically feasible process for dyeing of wool and silk fabrics at low temperature. Wool or silk fabrics are partially pre-swollen with dilute solutions of the two selected ionic liquids; 1 ethyl 3-methyl imidazolium acetate (EMIA), and 1-butyl 3-methyl imidazolium chloride (BMIC).

\section{Material}

\section{Experimental}

Pure light-weight merino wool fabrics were provided by Golden Tex Company, $10^{\text {th }}$ of Ramadan City, Egypt. The following table summarizes some properties of the used fabrics.

\begin{tabular}{|l|c|}
\hline Weight $/ \mathrm{m}^{2}$ & 160 \\
\hline Fibre diameter & 20 micron \\
\hline Tensile strength (warp) & $30 \mathrm{~kg}$ \\
\hline Tensile strength (weft) & $30 \mathrm{~kg}$ \\
\hline Elongation at break(warp) & $55 \%$ \\
\hline Elongation at break (weft) & $50 \%$ \\
\hline
\end{tabular}

Degummed woven silk fabric was provided by El-Khatib Co., Akhmeem, Egypt.

\section{Chemicals}

1- Ethyl 3-methyl imidazolium acetate (EMIA) was purchased from Io-li-tec, Denzlingen, Germany and 1-butyl 3-methyl imidazolium chloride (BMIC) from Merck, Steinheim, Germany. 1-Propanol was supplied from Riedel-de Haën, Seelze, Germany and Egyptol PLM nonionic detergent based on nonyl phenol ethoxylate from Starch and Brewer's Company, Alexandria, Egypt.

Dyes

Supranol Blue BLW (C.I. Acid Blue 203) was supplied by Egypt Colours Company, Cairo, Egypt. Lanasol Red 6G (C.I. Reactive Red 84) was kindly supplied by Ciba-Geigy, Switzerland; its reactive group is $\alpha$-bromo acrylamido group.

\section{Scouring of wool and silk}

Wool or silk fabrics were scoured in a bath containing $1 \mathrm{~g} / \mathrm{l}$ Egyptol PLM for $30 \mathrm{~min}$ at $60{ }^{\circ} \mathrm{C}$. The fabrics were then rinsed thoroughly with running water, squeezed, and air-dried.

\section{Treatment with ionic liquids}

Scoured wool or silk fabrics were immersed for $2 \mathrm{~min}$ in aqueous or nonaqueous solutions containing limited amounts (1-5\% w/w) of EMIA or BMIC in water or in 1-propanol with liquor-to-good ratio (L.R.) 30:1. The samples were mangle-squeezed to a pick up of $80 \%$ then heated for $6 \mathrm{~min}$ at various temperatures; $60-100{ }^{\circ} \mathrm{C}$, in case of EIMA, and $80-120^{\circ} \mathrm{C}$, in case of BMIC to evaporate and remove residual water or organic solvent.

Egypt. J. Chem. 54, No. 2 (2011) 


\section{Dyeing of wool and silk fabrics}

Dyeing of untreated as well as ionic liquid treated wool and silk fabrics was carried out using 1\% (owf) of Supranol Blue BLW (C.I. Acid Blue 203) at $60^{\circ} \mathrm{C}$, and $\mathrm{pH} 4.5$ using a liquor ratio of 1:50. On the other hand, dyeing of wool and silk fabrics with reactive dyes was carried out using $1 \%$ (owf) Lanasol Red $6 \mathrm{G}$ (C.I. Reactive Red 84) at $80^{\circ} \mathrm{C}$ and $\mathrm{pH} 5$ using liquor ratio 1:50. Aliquots of the dyeing bath were taken out every 5 min for determination of the extent of dye exhaustion after different periods of dyeing; the aliquots of dye liquor were added back to the dyebath after the measurement. The dyed fabric was squeezed and rinsed for four successive times with warm water (this is done to ensure nearly complete removal of last traces of ionic liquids and/or unfixed dyes) and air-dried. The dye exhaustion (\%) was estimated spectrophotometrically and recorded.

\section{Fastness to washing}

The colour fastness of the dyed wool or silk fabrics to washing was determined according to the AATCC test method 36-1972 using a laboratory laundrometer ${ }^{(13)}$.

\section{Fastness to rubbing}

The colour fastness to crocking (dry or wet) was determined according to the AATCC test method 8 - 1993. This test is designed for determining the degree of colour which may be transferred from the surface of the coloured fabrics to another white fabric by rubbing ${ }^{(14)}$.

\section{Scanning Electron Microscopy}

The untreated as well as the pre-swollen wool fabrics were mounted on aluminium stubs sputter coated with gold in an S150A sputter (coated Edward, UK), and examined by JEOL (JXA-840A) Electron Probe Microanalyzer (Japan).

\section{$X$-ray diffraction pattern}

The X-ray diffraction analysis was performed at room temperature for untreated and pre-swollen wool and silk fabrics on a Bruker D8 Avance using CUK as the target with secondary mono-chromator to operate at $40 \mathrm{KV}$ and $40 \mathrm{~mA}$. The scans were performed within the range of $4^{\circ}<2 \theta<60^{\circ}$ with scanning step $0.02^{\circ}$ in reflection geometry.

\section{Results and Discussion}

The effect of treatment of wool and silk with selected ionic liquids (ILs; namely 1-ethyl-3-methyl imidazolium acetate (EMIA) and 1-butyl-3-methyl imidazolium chloride (BMIC) on their dyeability with acid and reactive dyes was monitored (see structure 1: a-b below). Water or 1-propanol was used as diluents for the used ILs to decrease the amount of the used ILs and to minimize 
any deterioration that might take place to the substrate under the influence of the pure ionic liquid.<smiles>CCn1cc[n+](C)c1</smiles>

EMIA Structure 1a<smiles>CCCCn1cc[n+](C)c1</smiles>

BMIC

Structure 1b

Dyeing with acid dye (Effect of diluents)

Wool fabrics were immersed in 5\% (w/w) solution of EMIA in water or in 1propanol for $2 \mathrm{~min}$, followed by mangle squeezing to $80 \%$ pick up and the treated wool fabrics were dried at $100{ }^{\circ} \mathrm{C}$ for $6 \mathrm{~min}$. The dried samples were then subjected to dyeing with C.I. Acid Blue 203.

Figure 1 shows the effect of pre-swelling of wool with the EMIA/water or EMIA/propanol mixture on its dyeability with C.I. Acid Blue 203.

This figure clarifies that the dyeability of wool fabrics with C.I. Acid Blue 203 is remarkably enhanced upon pre-treatment in either EMIA/water or EMIA/propanol mixture, relative to the untreated wool. This is attributed to the swelling of wool fabrics under the effect of the used ILs mixtures; this ionic liquid has been reported as a swelling agent for cellulosic fibres by breaking the hydrogen bonds between its chains ${ }^{(15)}$. Similar effect would be expected in case of treatment of wool with the used ionic liquids.

The degree of enhancement in the dyeability of wool fabrics pre-swollen in EMIA/propanol mixture was found to be higher than those pre-swollen in EMIA/water mixture. This may be, due to faster evaporation of propanol from the pre-treated wool fabrics as compared with water, resulting in more effective swelling of the fabric by the remaining IL; higher volatility of propanol might be explained in terms of its relatively low heat of evaporation. Water molecules with lower molecular mass than propanol, are able to form relatively stronger hydrogen bonds with the ionic liquid.

Egypt. J. Chem. 54, No. 2 (2011) 


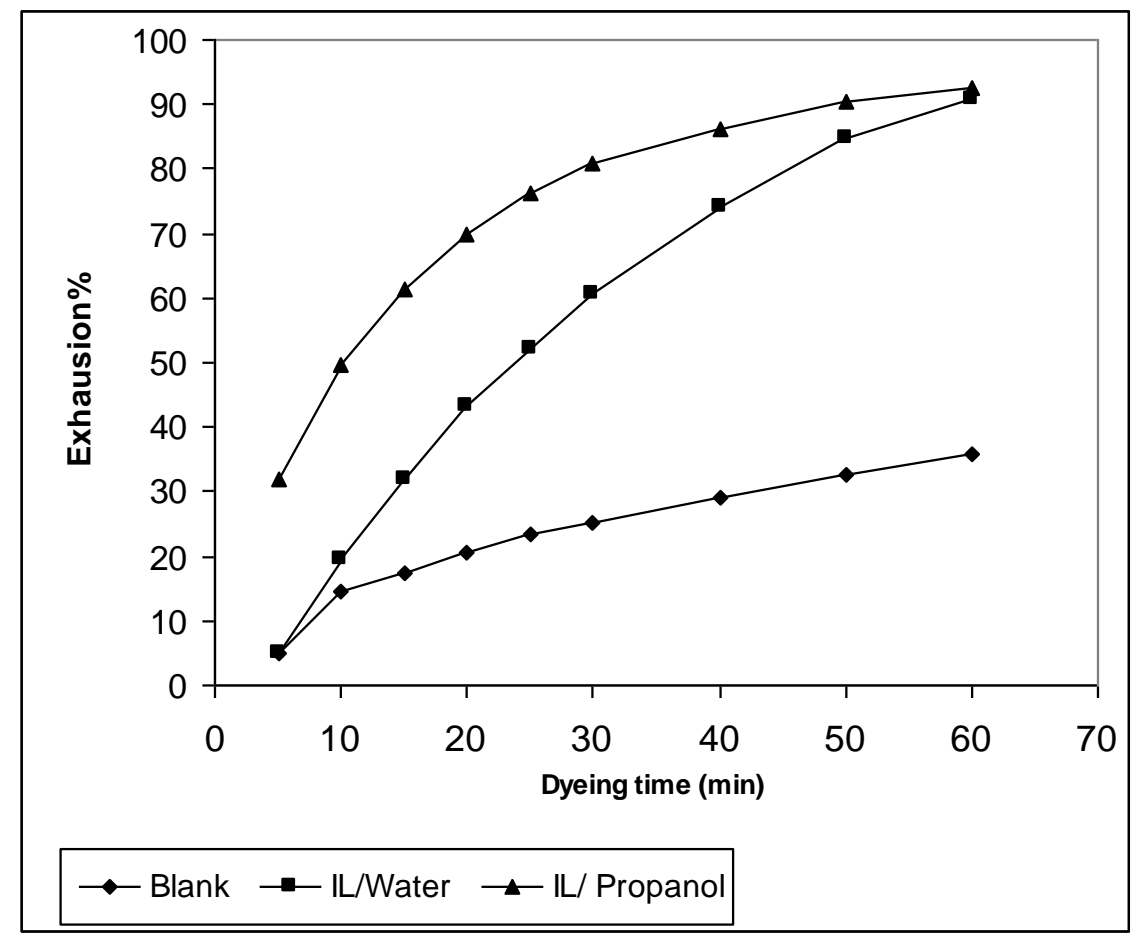

Fig.1. Dyeing of wool fabrics pre-treated with 5\% EMIA/propanol or EMIA/ water with C.I. Acid Blue 203 (shade: 1\%, L. R. 1:50 at $60^{\circ}$ C).

\section{Effect of propanol}

In order to assign whether the enhanced dyeability of wool fabrics pre-treated with EMIA/propanol is entirely due, to the effect of the IL, or partially, to propanol, a control wool sample, pre-treated with propanol was dyed with C.I. Acid Blue 203. Before dyeing, the propanol-pre-treated wool fabrics were dried at $100{ }^{\circ} \mathrm{C}$ for $6 \mathrm{~min}$.

Results of this investigation have shown that pre-treatment of wool fabrics with propanol alone gave the same trend of dyeability with the acid dyes, as that of untreated fabrics. This implies that the enhanced dyeability of the IL/propanol-treated wool fabrics is entirely due to the effect of the IL and not propanol.

Effect of nature and amount of ionic liquid

Wool fabrics were pretreated with different solutions containing different amounts (1-5\%) of 1-ethyl-3-methyl imidazolium acetate (EMIA) or 1-butyl-3methyl imidazolium chloride (BMIC). The effect of pre-swelling of wool on its dyeability with acid dye at $60{ }^{\circ} \mathrm{C}$ was assessed and illustrated in Fig. 2 and 3. 
These figures clarify that when the amount of IL increased from $1 \%$ up to $5 \%$, the dyeability of wool fabrics with C.I. Acid Blue 203 increased. This is due to the fact that as the amount of the ionic liquid increased, the degree of swelling of the fibres increased, and hence, the extent of dyeing of wool was enhanced.

Thorough investigation of Figures 2 and 3 indicates that, at all time intervals of dyeing, BMIC was found to be slightly more effective like EMIA in enhancing the dyeability of wool. It has been reported that the most dominant interaction was between the chloride anion of the IL and the hydroxyl groups in the substrate macromolecules. Chloride anion shows strong hydrogen-bonding basicity, while larger anions have weaker hydrogen bonding basicity ${ }^{(16)}$.

\section{Effect of drying temperature}

Wool fabrics were pre-treated with 5\% EMIA or BMIC followed by drying at various temperatures between $60-100{ }^{\circ} \mathrm{C}$, in case of EMIA, and $80-120{ }^{\circ} \mathrm{C}$, in case of BMIC. The drying step is essential to remove water or propanol from the fibre interior, leaving the IL of higher concentration inside the bulk of the fibre leading to fibre swelling.

Results shown in Fig. 4 and 5, clarified that, in both cases, as the drying temperature was increased, the dyeability of wool fabrics with Acid Blue 203 increased. It has been noticed that the drying of EMIA treated fabric at $100{ }^{\circ} \mathrm{C}$ or more resulted in yellowing of the dyed fabric and so drying at high temperatures should be avoided.

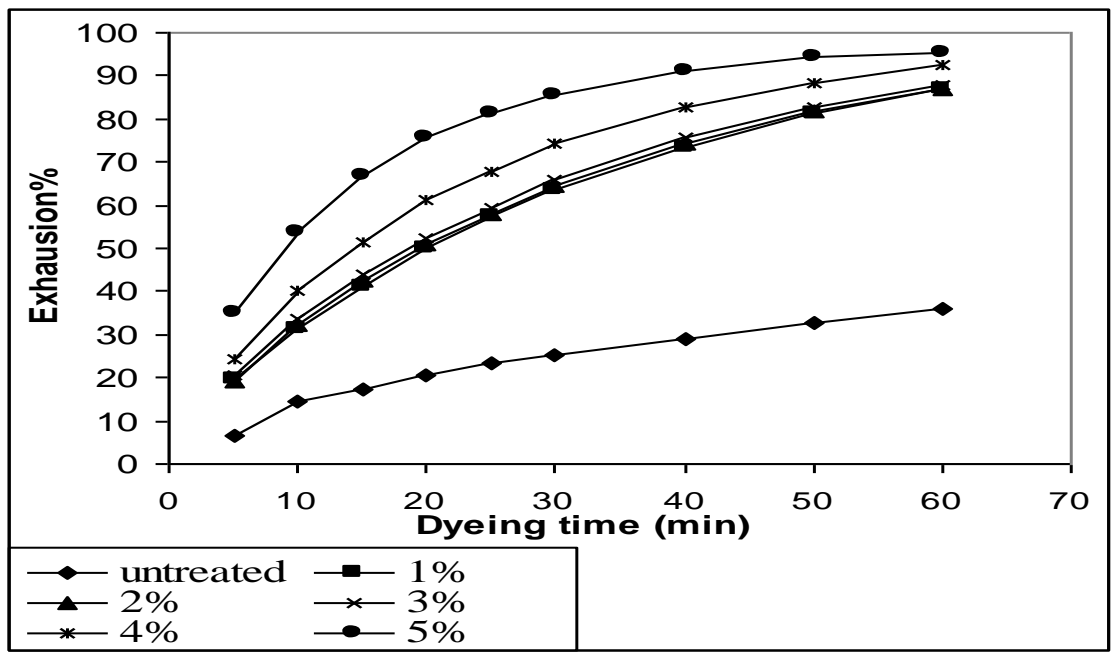

Fig.2. Effect of treatment of wool fabric with different amounts of BMIC (drying for 6 min at $120{ }^{\circ} \mathrm{C}$ ) on its dyeability with C.I. Acid Blue 203 (1\% shade, L.R. $1: 50$ and dyeing temperature $60^{\circ} \mathrm{C}$ ).

Egypt. J. Chem. 54, No. 2 (2011) 


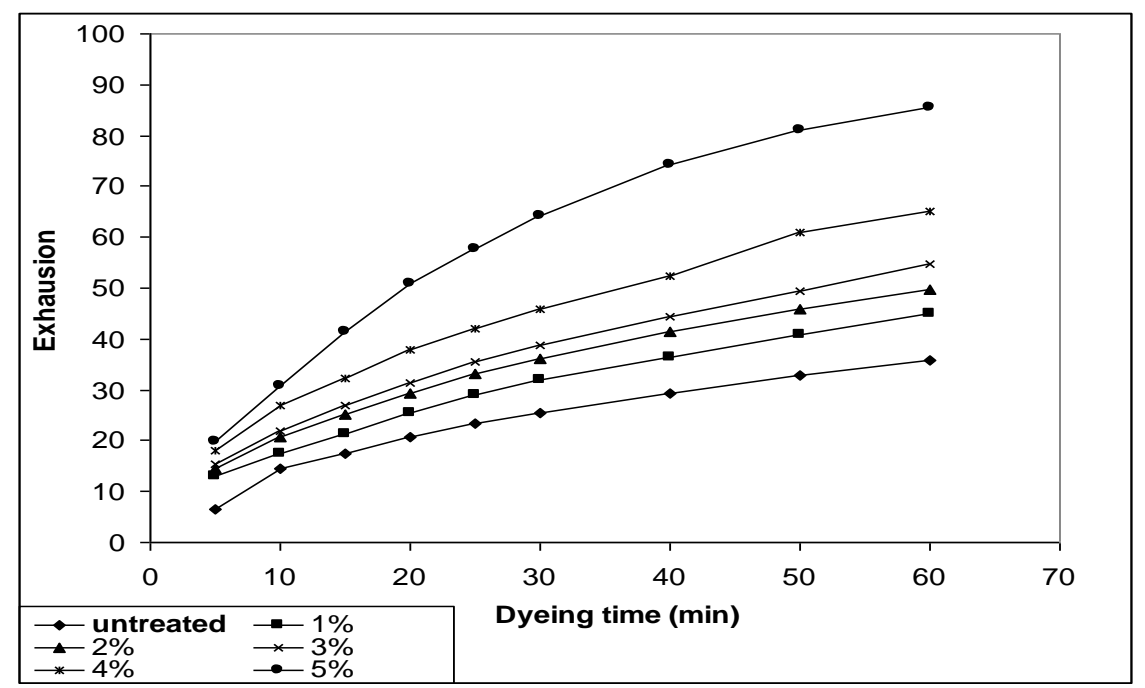

Fig. 3.Effect of treatment of wool fabric with different amounts of EMIA (drying for 6 min at $100{ }^{\circ} \mathrm{C}$ ) on its dyeability with C.I. Acid Blue 203 (1\% shade, L.R. $1: 50$ and dyeing temperature $60^{\circ} \mathrm{C}$ ).

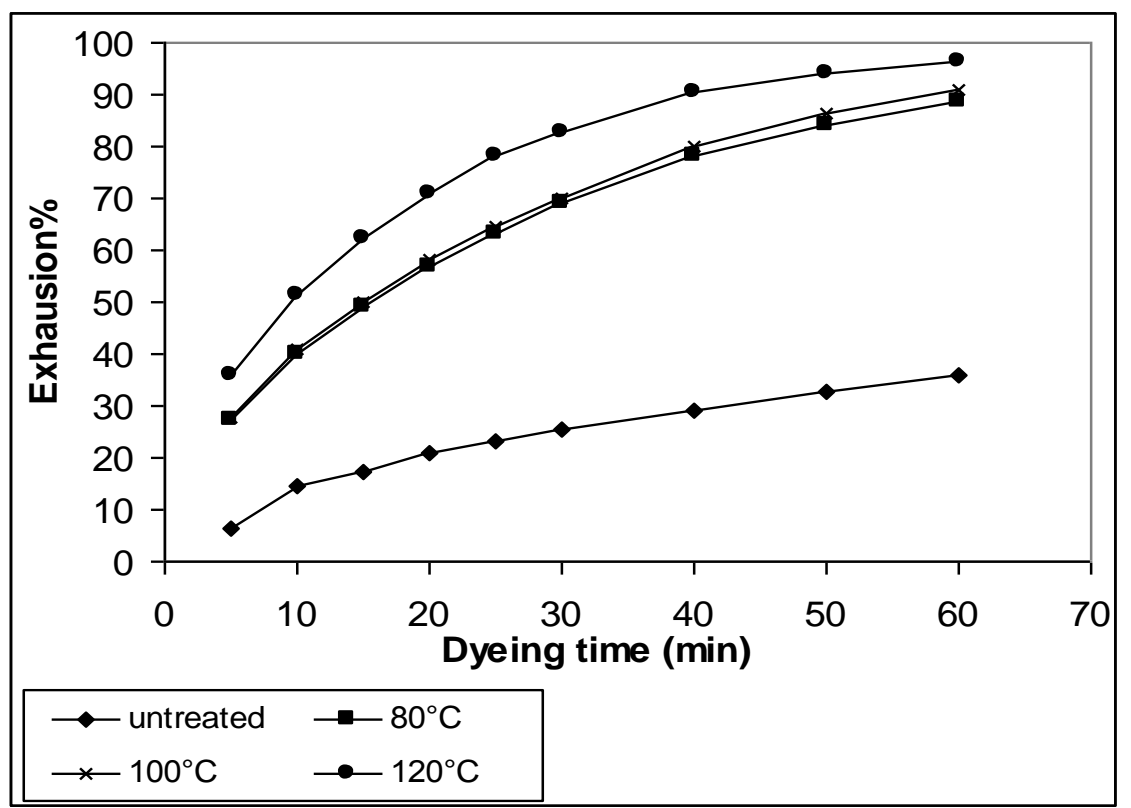

Fig. 4. Effect of pre-treatment of wool fabric with $5 \%$ BMIC followed by drying for 6 min at different temperatures on its dyeability with C. I. Acid Blue 203 (1\% shade, L. R. 1:50 and dyeing temperature $60^{\circ} \mathrm{C}$ ). 


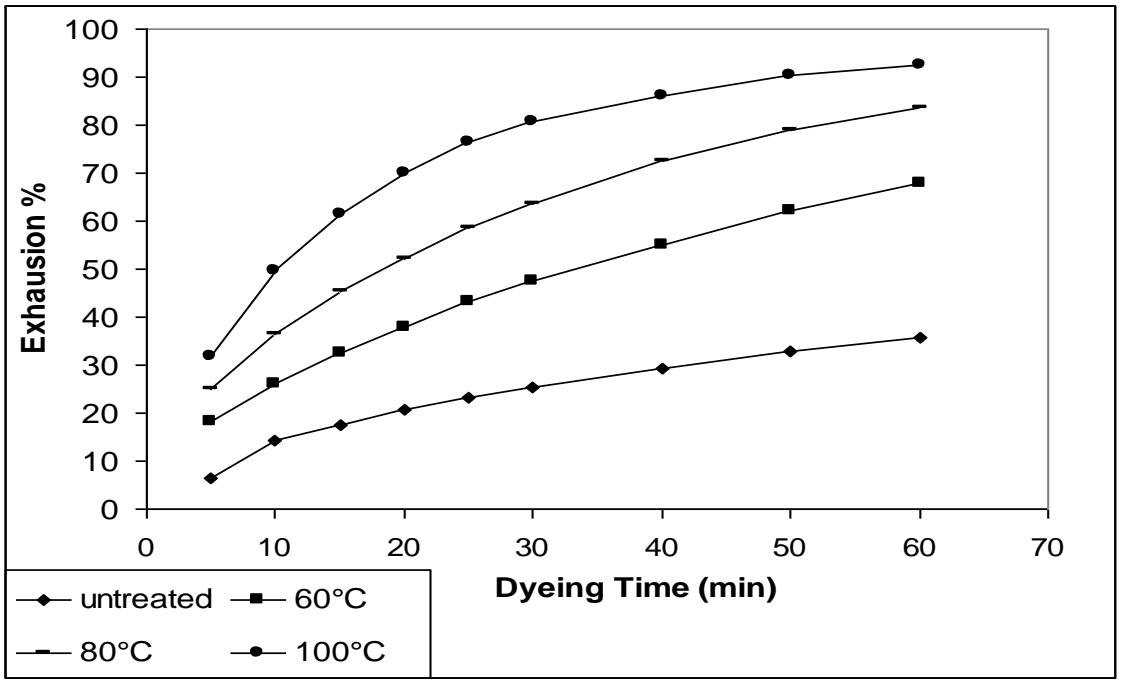

Fig. 5. Effect of pre-treatment of wool fabric with $5 \%$ EMIA followed by drying for 6 min at different temperatures on its dyeability with C. I. Acid Blue 203 (1\% shade, L. R. 1:50 and dyeing temperature $60^{\circ} \mathrm{C}$ ).

Dyeing with reactive dye

The effect of pre-treatment of wool fabric with EMIA or BMIC, on its dyeability with Lanasol Red 6G (C.I. Reactive Red 84) was investigated and summarized in Fig. 6.

This figure illustrates that the ability of BMIC in enhancing the dyeability of wool with C.I. Reactive Red 84 is nearly the same that of EMIA. This finding is similar to that obtained in case of dyeing with the acid dye Supranol Blue BLW. This assures that the improvement in the dyeability of the treated fabrics is due to physical effect and not to chemical modification of the fibre composition.

\section{Dyeing of silk}

Another investigation was conducted to study the effect of pre-treatment of silk fabrics with EMIA or BMIC, on their dyeability with Supranol Blue BLW (C.I. Acid Blue 203) and Lanasol Red 6G (C.I. Reactive Red 84).

Results shown in Fig. 7 and 8, indicate that treatment of silk with the said reagents resulted in complete exhaustion of the silk dyebath with or without ionic liquid treatment when using C. I. Acid Blue 203, presumably due to the high affinity of untreated or treated silk fabric with this acid dye. On the other hand, treatment of silk fabric with EMIA or BMIC, improved its dyeability with C.I. Reactive Red 84 as compared with the untreated silk (Fig 8). It is also observed that the extent of exhaustion of the reactive dye with silk is extremely lower than the extent of exhaustion with acid dye (Fig. 7). 


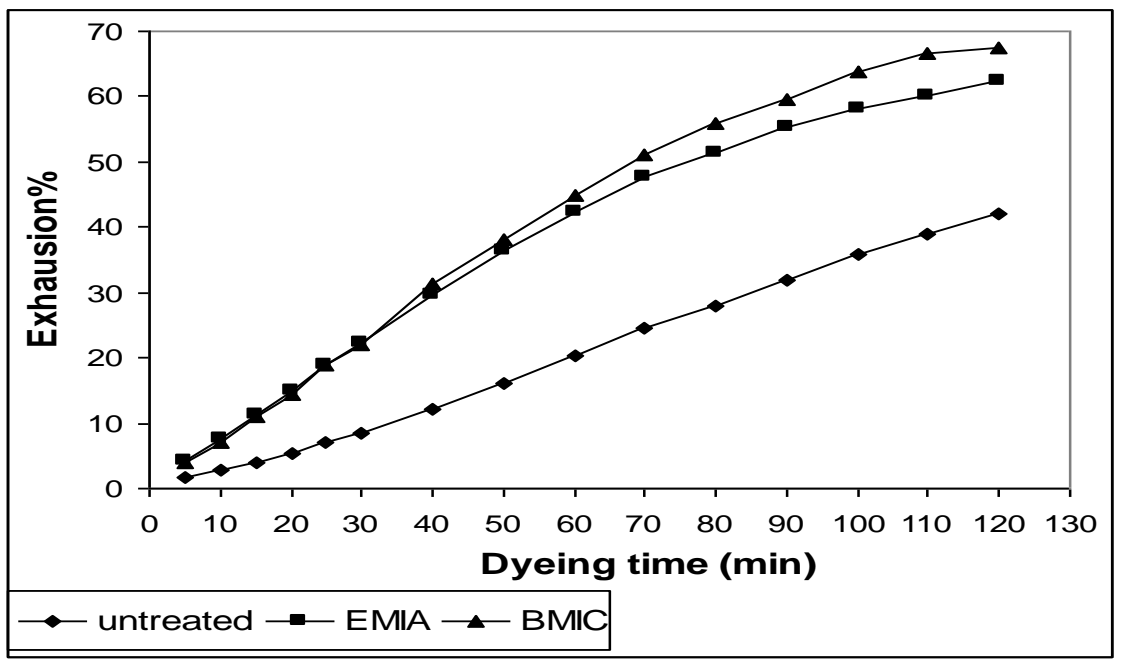

Fig. 6. Effect of pre-treatment of wool fabric with $5 \%$ EMIA (drying at $100^{\circ} \mathrm{C}$ ) or BIMC (drying at $120{ }^{\circ} \mathrm{C}$ ) for $6 \mathrm{~min}$, on its dyeability with C. I. Reactive Red 84 (1\% shade, L. R. 1:50 and dyeing temperature $80^{\circ} \mathrm{C}$ ).

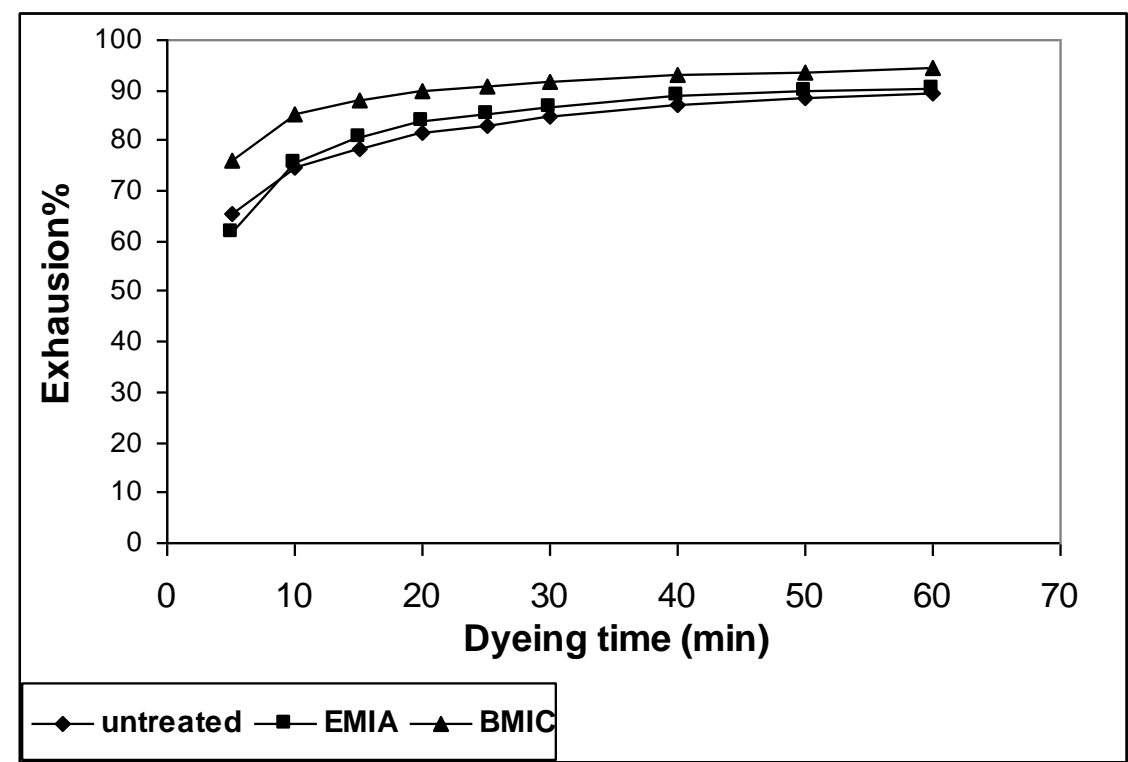

Fig. 7. Effect of pre-treatment of silk fabric with 5\% EMIA\&BMIC on its dyeability with C. I. Acid Blue 203 (1\% shade, L.R. 1:50, pH 4.5 and dyeing temperature $60^{\circ} \mathrm{C}$ ). 


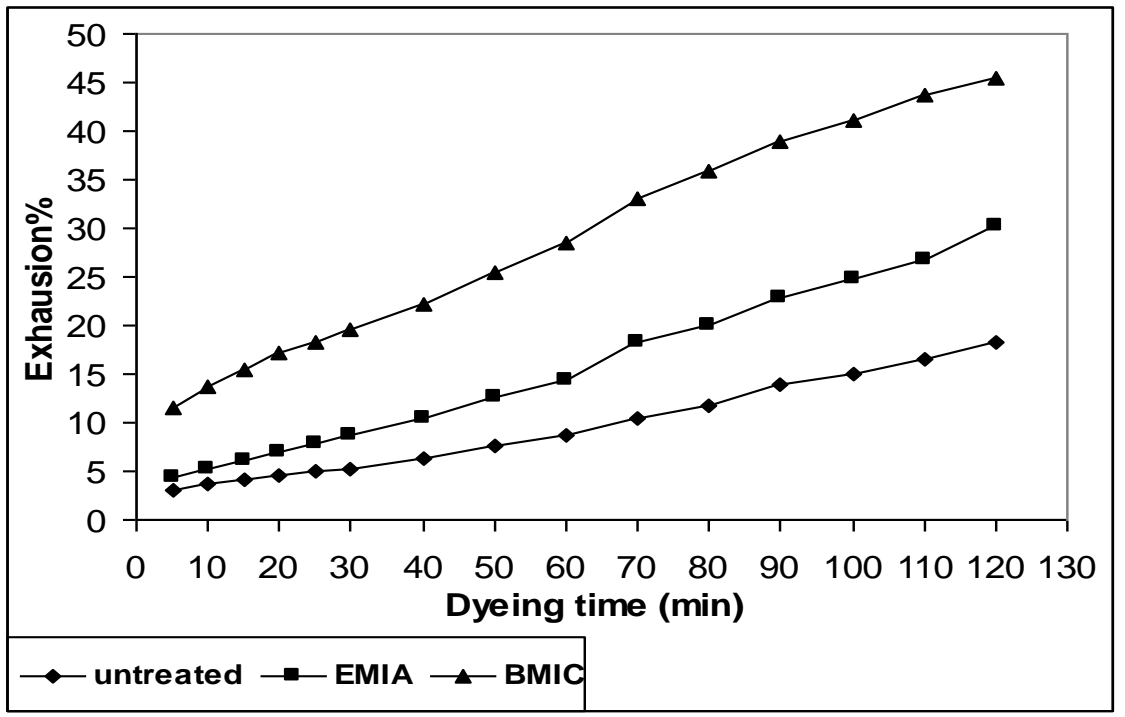

Fig. 8. Effect of pre-treatment of silk fabric with $5 \%$ EMIA\&BMIC on its dyeability with C. I. Reactive Red 84 (1\% shade, L. R. 1:50, pH 5, at $\left.80^{\circ} \mathrm{C}\right)$.

\section{Fastness properties}

Table 1 abridges the fastness properties of the dyed untreated as well as ionic liquid treated silk fabrics, to washing and rubbing. Data of this table clarifies that there is no significant change in the fastness properties to washing and rubbing between the untreated and the treated silk samples.

TABLE 1. Fastness properties of untreated as well as treated wool fabrics dyed with C.I. Acid Blue 203 or C.T. Reactive Red 84.

\begin{tabular}{|c|c|c|c|c|}
\hline \multirow{2}{*}{ Sample } & \multirow{2}{*}{ Dyeing process } & \multirow{2}{*}{$\begin{array}{l}\text { Washing } \\
\text { fastness }\end{array}$} & \multicolumn{2}{|c|}{ Rubbing fastness } \\
\hline & & & Dry & Wet \\
\hline Blank & & $4-5$ & 4 & $3-4$ \\
\hline $\begin{array}{l}\text { Treated with } 5 \% \\
\text { EMIA and dried at } \\
100^{\circ} \mathrm{C} \text { for } 6 \mathrm{~min}\end{array}$ & \multirow{2}{*}{$\begin{array}{c}\text { Supranol Blue } \\
\text { BLW (C.I. Acid } \\
\text { Blue 203) }(1 \% \\
\text { shade, L.R. 1:50 at } \\
\left.60^{\circ} \mathrm{C}\right)\end{array}$} & 4 & 4 & $3-4$ \\
\hline $\begin{array}{l}\text { Treated with } 5 \% \\
\text { BMIC and dried at } \\
100^{\circ} \mathrm{C} \text { for } 6 \mathrm{~min}\end{array}$ & & $3-4$ & $4-5$ & $3-4$ \\
\hline Blank & & $4-5$ & $4-5$ & $3-4$ \\
\hline $\begin{array}{l}\text { Treated with } 5 \% \\
\text { EMIA and dried at } \\
100^{\circ} \mathrm{C} \text { for } 6 \mathrm{~min}\end{array}$ & \multirow{2}{*}{$\begin{array}{l}\text { Lanasol Red } 69 \\
\text { (C.I. Reactive Red } \\
84)(1 \% \text { shade, } \mathrm{L} \text {. } \\
\text { R. } 1: 50 \text { at } 80^{\circ} \mathrm{C}\end{array}$} & $4-5$ & $4-5$ & $3-4$ \\
\hline $\begin{array}{l}\text { Treated with } 5 \% \\
\text { BMIC and dried at } \\
100^{\circ} \mathrm{C} \text { for } 6 \text { min }\end{array}$ & & $4-5$ & $4-5$ & 4 \\
\hline
\end{tabular}

Egypt. J. Chem. 54, No. 2 (2011) 


\section{$X$-ray diffraction}

In order to study the change in the fine structure of wool and silk fabrics after being pre-treated with selected ionic liquids, X-ray diffraction patterns for the untreated and pretreated wool and silk fabric were investigated. The characteristics of two main peaks for untreated and pretreated wool and silk fabrics (not shown here) clearly appeared as one intensive peak at $2 \theta=19.5^{\circ}$ for wool, $20.0^{\circ}$, and the others less intensive at $2 \theta=8^{\circ}$ for wool and silk. Remarkable broadening in the said two peaks in the pre-treated fabrics, relative to the untreated ones, indicates noticeable reduction in the crystal size ${ }^{(17)}$. The percentage of crystallinity in both treated and pretreated samples was estimated using the following equation ${ }^{(18)}$ :

$$
\% \mathrm{C}_{\mathrm{x}}=\frac{\mathrm{Ic}}{\mathrm{Ic}+\mathrm{Ia}} \times 100
$$

where $\% \mathrm{C}_{\mathrm{x}}$ is the crystallinty percentage and $\mathrm{I}_{\mathrm{c}}$ and $\mathrm{I}_{\mathrm{a}}$ are the intensities of $\mathrm{x}$-ray diffraction pattern of crystalline and amorphous components, respectively.

Data in Table 2 indicate that the degree of crystallinty of the pre-swollen wool and silk fabrics is remarkably less than those for the untreated samples. The minor change in d-spacing indicates that the ionic liquid can permeate into the semi-crystalline and amorphous phases, leading to reasonable decrease in crystallinty which leads to increase in dye exhaustion. It is worth mentioning that the findings of the X-ray investigation are in harmony with the results of dyeing exhaustion of the dyed wool and silk fabrics.

TABLE 2. Effect of pre-treatment on crystallinty and d-spacing of untreated and pretreated wool and silk fabrics .

\begin{tabular}{|c|c|c|c|c|c|c|}
\hline \multirow[t]{2}{*}{ Treatment } & $\begin{array}{c}\text { Crystallinity } \\
(\%)\end{array}$ & $2 \theta\left({ }^{\circ}\right)$ & $\begin{array}{c}\text { d-spacing } \\
\left(\mathbf{A}^{\mathbf{0}}\right)\end{array}$ & $\begin{array}{c}\text { Crystallinit } \\
\text { y (\%) }\end{array}$ & $2 \theta\left(\left(^{\circ}\right)\right.$ & $\begin{array}{c}\text { d-spacing } \\
\left(\mathbf{A}^{\mathbf{o}}\right)\end{array}$ \\
\hline & \multicolumn{3}{|c|}{ Wool fabric } & \multicolumn{3}{|c|}{ Silk fabric } \\
\hline Untreated & 55.9 & 19.20 & 4.48 & 87.8 & 19.99 & 4.30 \\
\hline EMIA & 50.8 & 19.46 & 4.56 & 85.9 & 20.19 & 4.39 \\
\hline BMIC & 50.4 & 19.79 & 4.62 & 77.5 & 20.23 & 4.40 \\
\hline
\end{tabular}

\section{Scanning Electron Microscopy}

The scanning electron micrographs of untreated as well as wool fabrics treated with either EMIA or BMIC were shown in Fig. 9-11.

Close investigation of these figures revealed that the morphological structure of wool was significantly modified as a result of pre-treatment with the said ionic liquids.

Whereas Fig. 9 shows the normal scaly structure of wool fibres, Fig. 10 reveals that there is partial removal and deterioration in the scales on the fibre surface; these scales are known to be hydrophobic in nature due to the presence 
of the lipid barrier on the wool surface ${ }^{(19)}$. Partial removal of this hydrophobic barrier, under the effect of EMIA, resulted in enhancement of any subsequent wet processes, such as dyeing.

Similar effects were observed in Fig. 11. Nevertheless, BMIC removes the lipid barrier from wool surface without drastic attack on the scaly structure of wool. Limited cracks are observed along the scales on the fibre surface. The enhanced dyeability of wool fabrics pre-treated with BMIC may be attributed to synergetic effect of removal of the lipid barrier from wool surface and/or the change in the crystal structure of the fibre interior.

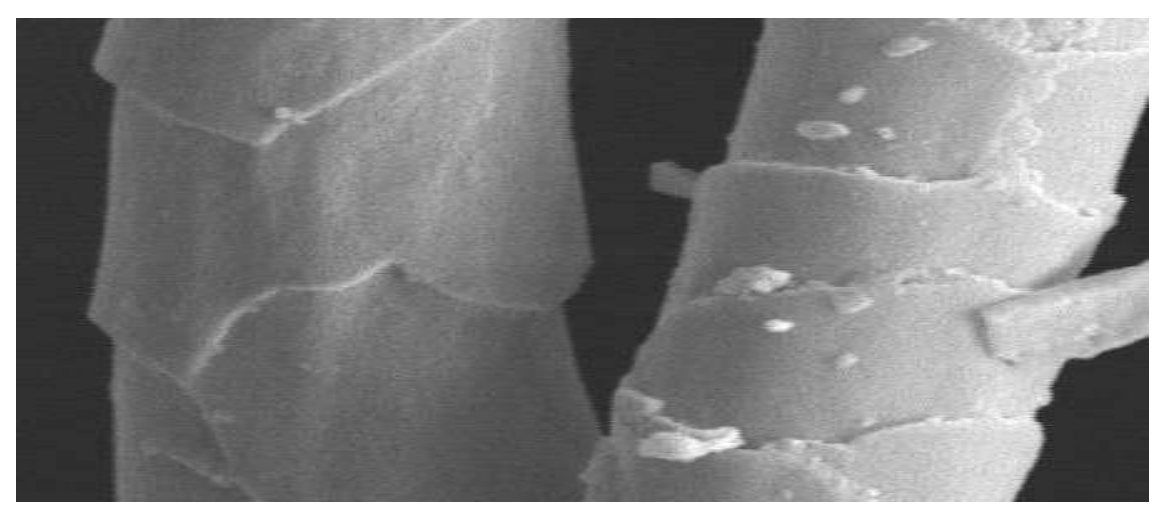

Fig. 9. Scanning electron micrograph of untreated merino wool fibre.

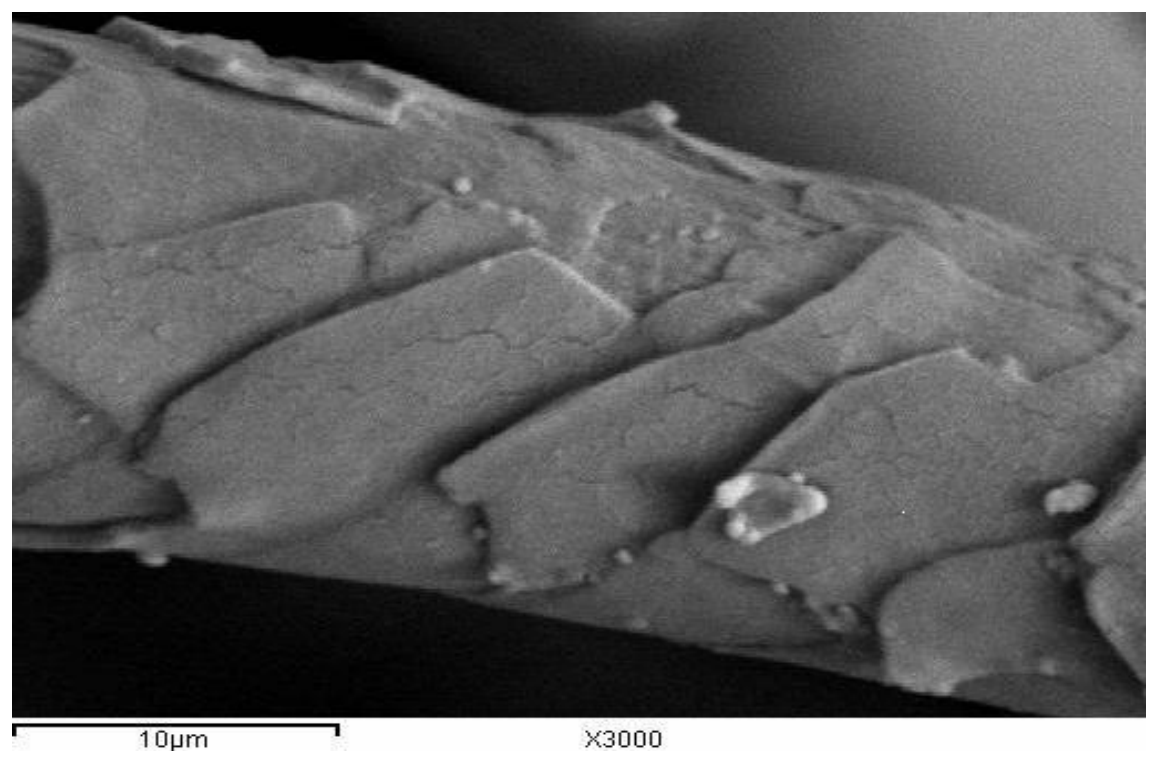

Fig. 10. Scanning electron micrograph of wool fabric pre-treated with 1-ethyl-3methyl imidazolium acetate.

Egypt. J. Chem. 54, No. 2 (2011) 


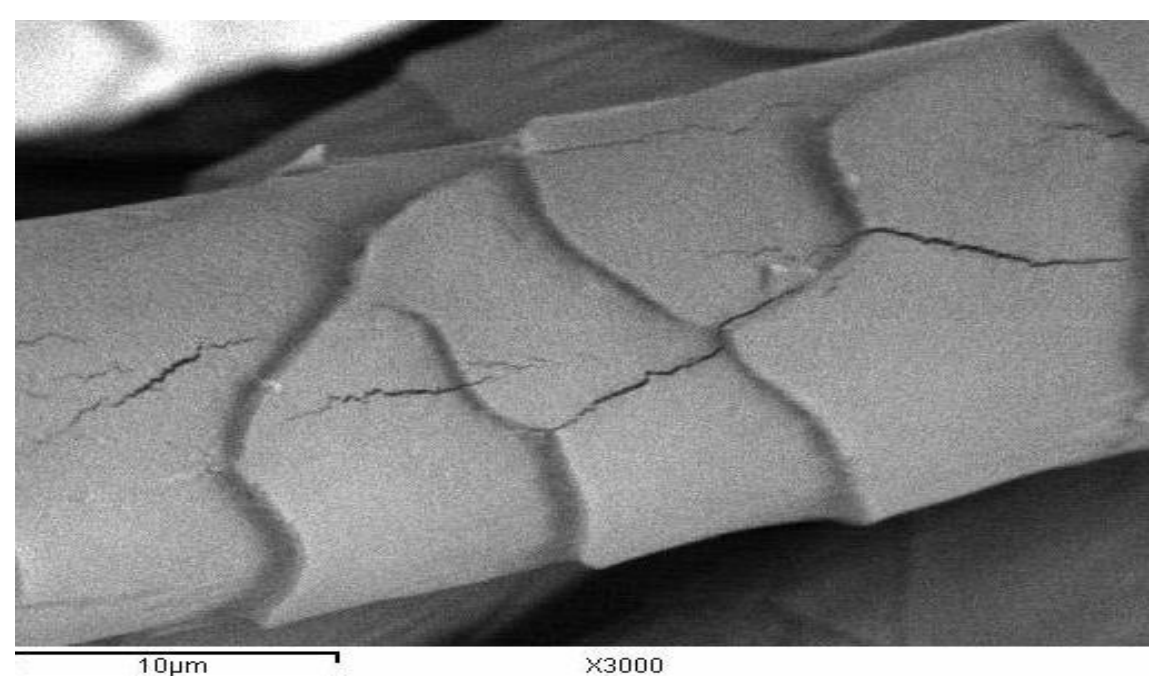

Fig. 11. Scanning electron micrograph of wool fabric pre-treated with 1-butyl-3methyl imidazolium chloride.

\section{Conclusion}

The ionic liquids 1-ethyl-3-methyl imidazolium acetate (EMIA) and 1-butyl3-methyl imidazolium chloride (BMIC) are found to be effective in enhancing the dyeability of wool and silk fabrics with acid and reactive dyes at low temperature to different extents depending on the substrate, dye, as well as reaction and dyeing conditions. Maximum enhancement in the dyeability was encountered upon treatment of wool fabrics with BMIC followed by with C.I. Acid Blue 203. Further study should be conducted on other ionic liquids in presence of other solvents to attain the optimum conditions used to enhance the dyeability of wool and silk with acid and reactive dyes.

\section{References}

1. Laus, G., Bentivoglio, G., Schotterberger, H., Kahlenber, V., Kopacka, H., Thomas R., and Sixta H., Ionic liquids: Current developments, potential and drawbacks for industrial applications. Lenzinger Berichter, 84, 71 - 85 (2005).

2. Halides and perhalides of the picolines. Amer. J. Chem. Soc. 21, 828 - 854 (1899).

3. Ramsay, W., On picoline and its derivatives. Phil. Mag. 2, $269-281$ (1876).

4. Jones, H. O., A study of the isomerism and optical activity of quinquevalent nitrogen compounds. J. Chem. Soc. Trans. 83, 1400 - 1421 (1903).

5. Harvey, A. W., A note on phenyldimethylallylammonium compounds. J. Chem. Soc. Trans. 85, 412 - 414 (1904). 
6. Wedekind, E., Ueber die Aethyl-allyl-methyl-phenyl-ammoniumjodide (XIV. Mittheilung über das fünfwerthige Stickstoffatom), Chem. Ber. 36, 3791 - 6 (1903).

7. Earle, M. J. and Seddon, K. R., Ionic liquids. Green solvents for the future. Pure Appl. Chem., 72(7), 1391-8 (2000).

8. Xie, H., Li, S. and Zhang, S., Ionic Liquids as novel solvents for the dissolution and blending of wool keratin fibers. Green Chem. 7, 606-8 (2005).

9. Sun, N., Swatloski, R. P., Maxim, M. L., Rahman, M., Harland, A. G., Haque, A., Spear, S.K., Daly, D.T. and Rogers, R., Magnetite-embedded cellulose fibers prepared from ionic liquid. J. Mat. Chem. 18, 283-290 (2008).

10. Hameed, N. and Gue, Q., Natural wool/cellulose acetate blends regenerated from the ionic liquid 1-butyl-3-methylimidazolium chloride. Carbohydrate Polymers, 78, 999-1004 (2009).

11. Sun, P., Liu, Z.T. and Liu, Z.W., Particles from bird feather: A novel application of an ionic liquid and waste resource. J. Hazardous Mat. 170, 786-790 (2009).

12. Rippon, J. A., "Wool Dyeing"; Chapter 1, p. 41, D. M. Lewis. (Ed); JSDC (1992).

13. Technical Manual of the American Association of Textile Chemists and Colourists, USA, Test Method 36 (1972).

14. Technical Manual of the American Association of Textile Chemists and Colourists, USA, Test Method 8 (1993).

15. Zhang, J., Ren, Q. and He., J. S. China Patent, ZL02147004.9 (2002).

16. Youngs, T.G.A., Holbrey, J.D., Deetlefs, M., Nieuwenhuyzen, M., Gumez, M.F.C. and Hardacre, C., A molecular dynamics study of glucose solvation in the ionic liquid 1,3-dimethylimidazolium chloride. Chem. Phys. Chem. 7, 2279 (2006).

17. Hsieh, Y.L. and Mo, Z., Crystalline structures of poly(ethylene terephthalate) fibers. J. Appl. Polym. Sci. 33, 1479 (1987).

18. Hinrichsen, G., Structural changes of drawn polyacrylonitrile during annealing. $J$. Polym. Sci. 38, 303 (1972).

19. Leeder, J.D. and Rippon, J.A., Changes indused in the properties of wool by specific epicuticle modification. J. Soc. Dyers \& Color. 101, 11 (1985).

(Received 23/5/2011;

accepted $17 / 7 / 2011$ ) 
إستخدام السوائل الأيونية لصباغة الأقمشة البروتينية عند درجات

عبد العزيز قنطوش ، عيد متولى خليل* ، سلوى موافى ، أميمة جابر علام وحسام السيد

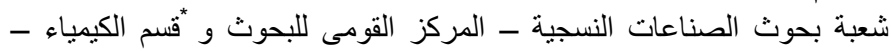

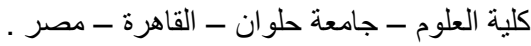

تم إستخدام السوائل الأيونية (BMIA-ethyl-3-methyl imidazolium acetate (EMIA)

1-butyl-3-methyl imidazolium chloride (BMIC)

أقششة الصوف والحرير بإستخدام الصبغات الحامضية أوالنشطة عند درجات

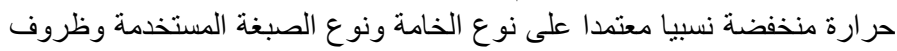

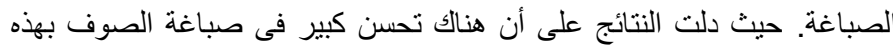

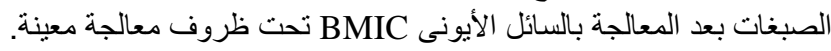

